\title{
Walzer, Michael. 2004. REFLEXIONES SOBRE LA GUERRA. Barcelona: Paidos, 203 PP.
}

El trabajo de Michael Walzer, Reflexiones sobre la Guerra, reúne un conjunto de estudios y ensayos, ya publicados en versiones preliminares en Alemania, bajo el título Erklärte KriegeKrieserklärungen (Hamburg: Sabine Groenewold Verlag, 2003), y más recientemente en inglés bajo el título Arguing About War (New Haven: Yale University Press, 2004)1. En la misma línea de otras investigaciones ya publicadas por el autor -Just and Unjust Wars, (New York: Basic Books, 1997), los estudios y ensayos del libro contienen análisis ético-políticos sobre la guerra y ejemplos de casos históricos.

Mientras en la primera parte Walzer presenta razonamientos éticos en relación con la disuasión nuclear, el terrorismo y la intervención humanitaria ${ }^{2}$, en la segunda incluye estudios de caso, todos los cuales fueron escritos como respuestas frente a guerras y conflictos armados concretos ${ }^{3}$. En el tercer capítulo incluye también un ensayo de perspectiva prospectiva sobre las implicaciones de diversos tipos de regímenes internacionales en relación con la guerra.

El autor retoma y profundiza argumentos ya formulados en otros trabajos sobre la condición moral de la guerra como actividad humana. No obstante ser una actividad infernal, en ella existe una "justicia de guerra". El calificativo de justicia o guerra justa significa, en primer término, que sea justificable, defendible moralmente, dadas determinadas circunstancias y alternativas de decisión, por ejemplo actos de agresión y de crueldad que dañan la conciencia moral del ser humano. En este sentido, y en consideración a las circunstancias atroces de ciertos conflictos locales, regionales, nacionales o internacionales, Walzer defiende con mayor énfasis que en otros escritos anteriores la justicia de las intervenciones. Walzer se pregunta quién, cómo y cuándo ha de intervenir, y responde que cuando los crímenes causan grave conmoción al resto del mundo, cualquier actor en condiciones de detener esta situación no sólo puede intervenir, sino que debe hacerlo. Ciertamente, no existe una entidad u organización determinada que se encuentre investida a priori con la facultad de intervención.

Los argumentos de la justificación de la guerra se inscriben en la tradición del razonamiento ético desde el derecho natural, ius ad bellum (derecho de ir a la guerra) y ius in bello (conductas justas durante la guerra). Walzer se esfuerza por ampliar la teoría de la guerra justa al ius post bellum (la

1 Asimismo, las primeras versiones de varios de estos artículos han sido publicadas en diversas revistas académicas y de circulación períodica (Social Research, Parameters, Dissent, The New Republic, Le Monde, Frankfurter Rundschau, The New York Review of Books, The New York Times, entre otras).

2 Triunfo de la teoría de la Guerra Justa, tipos de responsabilidad militar, la ética en situaciones de emergencia, crítica de las excusas del terrorismo, la política de las intervenciones.

Guerra del Golfo, Kosovo, la Intifada, las guerras de Israel y Palestina, el 11 de septiembre y el terrorismo, Irak. 
justicia de la posguerra), en razón de los problemas concretos que han dejado planteados conflictos armados tales como el de Kosovo, Timor Oriental y, más recientemente, Irak. La argumentación del autor tiene el propósito de formular normas morales mínimas que puedan llegar a ser compartidas por toda la humanidad.

En este trabajo, el autor procura explicitar reiteradamente su postura ética y política sobre la cuestión de la guerra, situación que lo lleva a un distanciamiento de las posiciones realistas y pacifistas4. Las guerras no ocurren por una necesidad cuasi-mecánica y el argumento realista de la necesidad sólo puede ser formulado en retrospectiva. En los hechos, lo que pudiese parecer inevitable está mediado por un proceso de deliberación política, donde hay espacio y posibilidades para tomar diversas decisiones. Por otra parte, la voluntad de abolir la guerra una y otra vez entra en contradicción con la realidad. Por las razones indicadas, ante lo inevitable de la guerra, según Walzer, la práctica del discernimiento racional y los procesos de deliberación constituyen imperativos morales y, al mismo tiempo, criterios con respecto a la calidad moral de los resultados.

Al igual que en otros trabajos, el juicio crítico del autor y su pasión dan cuenta de una reflexión renovada sobre el fenómeno de la guerra que, según el mismo indica en su introducción, "es una actividad necesaria de los ciudadanos demócratas" (Walzer, 2004, 19).

Patricio Valdivieso

Instituto de Ciencia Política

Pontificia Universidad Católica de Chile 